Article

\title{
Optimisation of Multipurpose Reservoir Operation by Coupling Soil and Water Assessment Tool (SWAT) and Genetic Algorithm for Optimal Operating Policy (Case Study: Ganga River Basin)
}

\author{
Jatin Anand * (1), Ashvani Kumar Gosain and Rakesh Khosa \\ Department of Civil Engineering, Indian Institute of Technology Delhi, New Delhi 110016, India; \\ gosain@civil.iitd.ac.in (A.K.G.); rakesh.khosa@gmail.com (R.K.) \\ * Correspondence: cez138430@civil.iitd.ac.in
}

Received: 2 April 2018; Accepted: 9 May 2018; Published: 21 May 2018

\begin{abstract}
Reservoirs are recognized as one of the most efficient infrastructure components in integrated water resources management. At present, with the ongoing advancement of social economy and requirement of water, the water resources shortage problem has worsened, and the operation of reservoirs, in terms of consumption of flood water, has become significantly important. To achieve optimal reservoirs operating policies, a considerable amount of optimization and simulation models have been introduced in the course of recent years. Subsequently, the assessment and estimation that is associated with the operation of reservoir stays conventional. In the present study, the Soil and Water Assessment Tool (SWAT) models and a Genetic Algorithm model has been employed to two reservoirs in Ganga River basin, India in order to obtain the optimal reservoir operational policies. The objective function has been added to reduce the yearly sum of squared deviation from preferred storage capacity and required release for the irrigation purpose. The rule curves that were estimated via random search have been discovered to be consistent with that of demand requests. Thus, in the present case study, on the basis of the generated result, it has been concluded that GA-derived optimal reservoir operation rules are competitive and promising, and can be efficiently used for the derivation of operation of the reservoir.
\end{abstract}

Keywords: reservoir operation; SWAT; genetic algorithm; Ganga River

\section{Introduction}

The apprehensions pertaining to the water and their demands in the existing and foreseeable future will continue to be progressively onerous and would turn out to be increasingly intertwined with several evolving segments, viz. farming, industries, and manufacturing [1-3]. The impacts of alterations in the global climate has intensified furthermore to these challenges; thus, problems pertaining to water shortage demand more attention and additional actions [4-6]. There is increasing apprehensions regarding the requisite to formulate the balance between water demands and corresponding rivalling sectors, especially in river basins in which the majority of the water is allotted or exhausted. As a consequence of the increase in population and various socio-economic advancement in the recent decades within the Ganga River Basin, the demand as well as the claim for the available water has swollen, and assessing the demand and supply of available water turns out to be essentially urgent [7-9]. Most tropical and sub-tropical areas, such as India, which is categorized by considerable annual and seasonal variations in precipitation. Such variability steps up the need for the development of infrastructure and the necessity for the management of available water resources in a sustainable and economic manner. The system analysis methodology stands out as the most significant enhancement 
in the field of management of water resources, and has vast prospective in stipulating the applicable provision for potent and efficient administration in the evolving circumstance [10-12]. The downstream area of the Ganga River has undergone a tremendous amount of increase in population and intense agricultural and industrial expansion has all induced a considerable increment in the requirement of need of water. The demand for water from the regions outside of this basin is also escalating. Hence, defining techniques that can accomplish a safe, assured, secure, and sustainable supply of water in this region has caught the attention of both society and government $[13,14]$.

In recent decades, considerable study has been conducted exercising optimization of reservoir to ascertain the optimal and efficient operating policies [15-18], and the stated area has developed into a major topic in examining the sustainability of existing water resources $[16,19,20]$. To curb the problem of inadequate supply of water during lean season, focus has been given on improving management of existing water resources, especially in the optimization of operations and the policies of reservoir $[18,21,22]$. Reservoirs has the ability to boost the dependability of water supply in fostering livelihoods, increasing agricultural yield, and reducing the susceptibility of farmers to droughts. A reservoir could suffice different objectives through water impounding and streamflow regulatory. Regular reservoir operational objectives comprise of the control of flood, generation of hydropower, agricultural, industrial and domestic supplies of water, navigation, recreation, and so on $[10,22,23]$. Moreover, the ecological and environmental issues that can result from the operation of reservoir and diversion of water have also appealed to stakeholders and decision makers [24-26]. Usually, most of the reservoirs all around the world are accomplished by employing predefined operating policies $[17,20,27,28]$. Operating policies of reservoirs have been aimed for regulating the release of water by keeping in mind the interests of the reservoir stakeholders and decision makers, volume of water impounded, inflows, demands of water, release capacity, and downstream constraints [29-31]. Loucks and van Beek, (2017) [32] mentioned two types of operating policies in their study; one distinguishes the target water storage for a specific time, which is typically a distribution rule based on single objective storage curve, whereas the second one categorizes the reservoirs storage zones exercising various rule curves that are correlated by specific distribution policies. In addition to an exemplary operating policy should not only enhance the performance of the corresponding reservoir (e.g., reduce deficit in supply of water and boost monetary profits), although should also be able to accomplish the preservation of hoarded water inside the reservoir [17,33-35]. However, more often than not there is the circumstance that a predefined policy could not able to accomplish the objectives of a best policy. Thus, the enhancement of the operational policy of the reservoirs is essential $[27,36]$, and the simulation of reservoirs along with the optimization algorithms can be an efficient and effective methodology for fine-tuning the rule curves [16,35]. The operation of the reservoir is a large scale multi-objective optimization problem, involving agriculture, hydrology, hydropower, reliability, and environment flows [37-39].

The development of operation of reservoir is a complicated problem, which includes multiple decision variables, several conflicting and contradictory objectives together with significant uncertainty and risk $[16,28,36]$. Designing and attaining operating rules for multi-reservoir structures is a challenging job and has been extensively generated during the scientific past of researches that are associated with the management of water resources [30,31,40]. Conventionally, operation of reservoir is accomplished based on heuristic measures, comprising storage curves and skewed decisions made by the decision makers to release water from the reservoir conferring upon the existing stage of the reservoir, prevailing water demands, current hydrological conditions, and the period of the year. The expression rule curve has been predominantly utilized to represent the operational policies that outline the best or optimum level of storage and render a tool for release policies i.e., recognised as a function of stored water [41,42]. The problem becomes even more complex and intricate when the constraints or the goals that are associated to quality of water are taken into consideration $[28,43]$. In the last decade, an array of approaches has been formulated based not only on conventional stochastic and probabilistic investigations, but also on the data and the estimation 
of critical hydrologic events, keeping in mind the end goal to build the efficiency and efficacy of the reservoir $[44,45]$. The operation of the reservoir is a non-convex and nonlinear problem, however few of the academicians have employed a linear method to incorporate the methodology of linear programming for recommending their solution [23,46]. Reliability is the major concern among the researchers and necessitates that a complete stochastic approach is applied to decipher the problems of reservoir operation, and yet, only some of the researchers have undertaken to addressed this issue $[17,47]$.

A numerous amount of computer-based analytical techniques, from computation to optimization, are propounded for articulating, analysing, investigating, evaluating, and explaining problems pertaining to water resources planning and management [11,13,32]. In the initial years, the majority of the optimization methods for the analysis of water resources systems incorporated dynamic programming (DP), linear programming (LP), and several nonlinear programming techniques. Several studies that are associated with water resources have previously applied these techniques complemented by auxiliary methods for a diverse range of problems [32,48,49]. Rapid advancements have transpired in these subjects, aided by high-speed computers, which have attributed to its development. During last decades, evolutionary optimization methods, viz. genetic algorithms, have become popular in the application of global optimization in the field of planning and management of reservoirs $[16,18,20,22,23,27,35,36,50]$. While, almost all of the prevalent algorithms are accomplished in undertaking complicated and complex planning and management problems, evolutionary algorithms methods have been able to attract a vast amount of consideration vis-à-vis, their capability in optimizing complex systems $[31,34,44]$. Advancement in high speed computing techniques have led to a vast number of researches, which employed evolutionary algorithms (EAs) to different disciplines of water resources planning, operational and management problems [13,23], involving the calibration of surface and ground-water [51,52], treatment of water [53], and operation policy of reservoirs [16,30,31]. Moreover, Abraham and Jain, (2005) [54] indicated that there are numerous advantages in employing EAs since they demand comparatively less understanding regarding the prevailing questions being answered, are little susceptible to the Pareto front's continuity or their shape, are robust and could be easily implemented. The competence of EAs on anonymous objective functions involving several numerical and scientific characteristics, viz. non-differentiable, discontinuous, non-convex, and multimodal [23,31,46], have been accounted in numerous researches. Evolutionary algorithms (EAs) have been comprehensively employed to a number of extents of water resources over the last decade, such as urban drainage and sewage schemes [55], water distribution systems [39,56], hydrologic and fluvial models [1], and water supply and sewage treatment systems [13,44,55].

GAs, which were initially ascribed by Holland, (1975) [57] and further developed by Goldberg, (1989) [58], have been one of those developments that has offered a potent tool for optimization. GAs, analogous to natural selection based on the renowned Darwinian theory, take into account the native genetic operators and the continued existence of the fittest in an effort to obtain the optimal solution in a considered set of solution $[10,17,32,56]$. They have become a handful tool for answering complicated problems of optimization in several different disciplines. Following the introduction of GA and its comprehensive utilisation in the different disciplines of water resources planning and management problems. Over the years, GAs have gained attention in the field of global optimization application to address storage reservoir optimization operation, planning and management $[18,30,31,41,43,47,59]$. Chang et al. (2005) [18] employed a GA-based methodology to explore the optimal operational policy for the releases of water from reservoir, and then utilised these results in a developed ANFIS model. Oliveira and Loucks, (1997) [60], who applied GA to assess operating policies for multi-reservoir systems, establish that it could be successfully utilised in determining the efficient and the successful operational rules. Wardlaw and Sharif, (1999) [37] also applied GAs to answer the reservoir operation problems optimally. Yuan et al., (2008) [61] applied an advanced differential EA for optimal scheduling of hydro generation on a daily basis. Numerous researches have used EAs to manage the reservoir management problems realistically, particularly the scheduling of release from the reservoir and 
the planning for hydropower generation [10,16,20,23,31,33,62-64]. Today, especially for reservoirs operation problems, EAs are acknowledged as suitable tools to support decision-making due to their multiple advantages.

The reality of an ever increasing urban population coupled with socio-economic advancement during the last few years encompassing the Ganga River Basin (GRB), has substantially increased the requirement of water, besides, the boundless need of the water management practices necessitates the study evaluating the water supply security $[65,66]$. Moreover, anthropogenic activities, for example, river operations and extensive regulations have tremendously significantly altered the water budget of the basin. In addition, the ecological and environmental problems that are associated with the operation of reservoir and the diversion of water have likewise appealed to the concern of the society and government $[6,67]$. Moreover, areas in the downstream part of the Ganga River have witnessed ever increasing growth in the population and intense agricultural and industrial advancement, leading to a considerable surge in the demand of water. Therefore, finding modes of water supply to attain a safe, economical, sustainable, and secure supply in this area, have enticed government, stakeholders, policy makers, decision makers, and society.

As explained before, the water demand of this basin is also rising. Consequently, discovering techniques that can accomplish a safe, assured, secure, and sustainable supply of water in this region has catch the attention of both society and government. Nevertheless, the simulation of credible flows for GRB is the primary step before heading towards the optimizing of reservoir operation problem, as it is necessary not only to manage the available water resources of the basin, but also to have a enhanced knowledge of the influence of possible future alterations on the availability of water [9]. Hydrological models have been necessary for examining hydrologic processes and their reactions to both endogenous and human influences, although because of the complexity involving the exemplification of complicated environmental conditions and processes, the hydrologic models require to be calibrated prior to its application in order to attain a realistic match [68-70]. Especially, water yields, inflows, irrigation water demand, and overall water balance of a watershed can be simulated through the hydrologic simulations by the Soil and Water Assessment tool (SWAT) [71,72].

The objectives of this research have been to (1) compute a range of demands of water (e.g., irrigation requirement) in the GRB; and, afterwards, (2) figure out different optimal approaches for two distinctive reservoirs for different priorities to warrant the river's environmental health, while minimalizing the deficit in supply of water and amplifying the generation of hydropower as well.

\section{Study Area}

A multi-objective optimization model has been introduced to assist the operation of the reservoir in this study, for which two reservoirs, namely Rihand dam and Tehri Dam, in the Ganga River Basin, India has been chosen to examine the new model.

\subsection{The Ganga River Basin}

GRB encompasses an area of about $1.08 \mathrm{Mkm}^{2}$ and it canvases a distance of $1200 \mathrm{~km}$, before confluencing into the Bay of Bengal in the east. The Ganga River basin is located in the northern side of the Indian sub-continent, which is encompassed within the latitudes of $22^{\circ} 30^{\prime}$ and $31^{\circ} 30^{\prime}$ North and the longitude of $73^{\circ} 30^{\prime}$ and $89^{\circ} 00^{\prime}$ East (Figure 1). The basin area of $0.86 \mathrm{Mkm}^{2}$ in India, which is almost equal to the 26 percent of overall geographical area of the India, is distributed between eleven states. The average annual rainfall in the GRB varies from $350 \mathrm{~mm}$ at the western end to $2000 \mathrm{~mm}$ near the delta at the eastern part. The amount of rainfall received by the basin not only changes throughout the region, but it is also limited to only a few months of the year mainly during the months of monsoon extending from June to October, thus instigating low flow situations in the Ganga as well as its tributaries throughout the dry season of November through May. Therefore, because of both intra and inter annual unevenness in precipitation and consequently in surface runoff, the realistic 
distribution and allotment of water from the river through reservoirs is necessary for preserving, sustaining, exploiting, and managing water resources in this area.

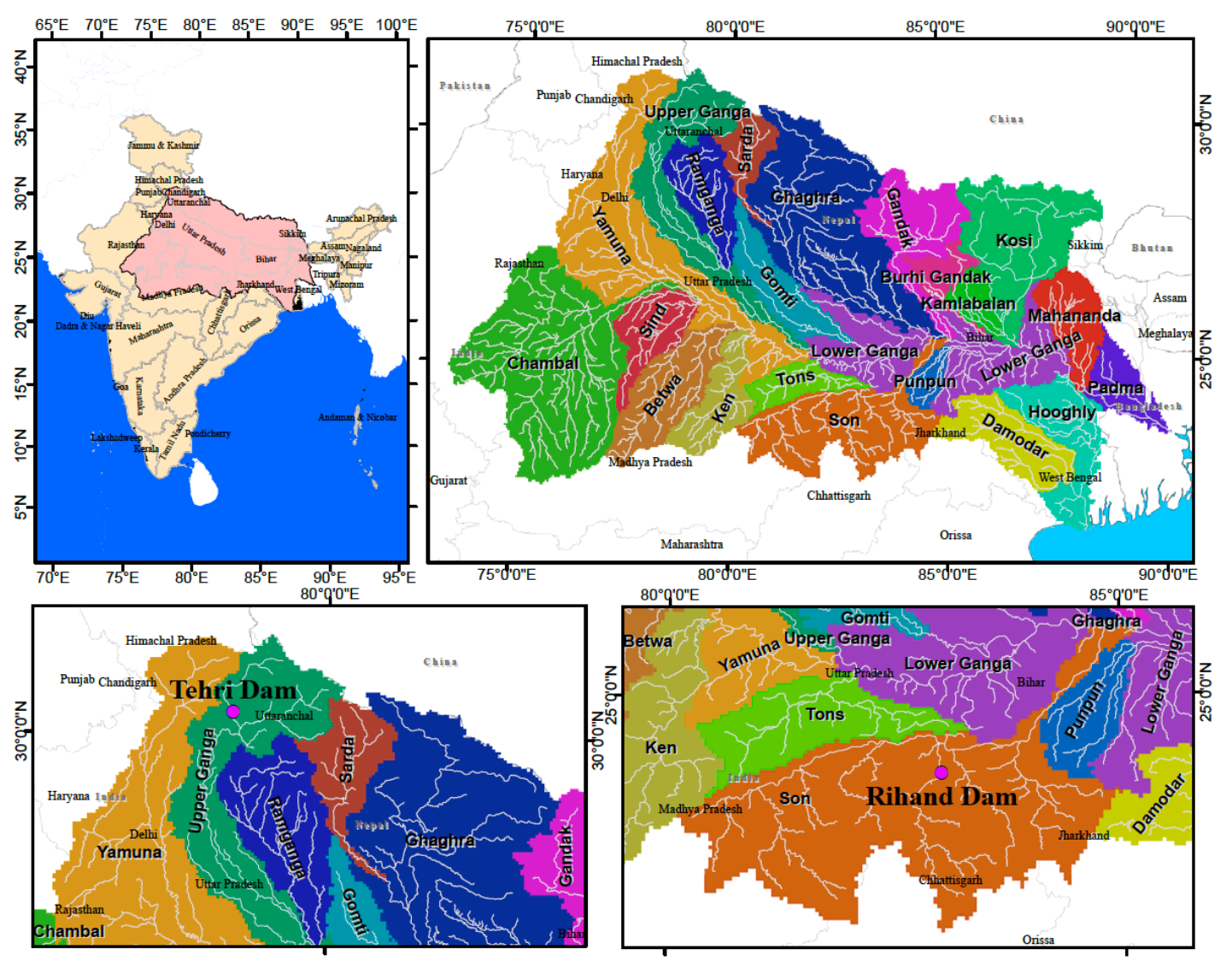

Figure 1. Location of the Ganga River Basin in India.

\subsection{The Reservoirs}

Rihand dam is one of the Asia's largest man-made reservoirs developed. Reservoir's total area is roughly $457 \mathrm{~km}^{2}$. Total area of submergence is approximately 46,600 ha (Table 1 ). The reservoir is a multipurpose and multiyear structure, which commenced its operation in 1962. Thus, the reservoir is of utmost importance to the people of the area. The released water courses towards north across the industrial regions and meets the Son River near Chopan. The water of reservoir is primarily utilised for:

(a) drinking;

(b) irrigation;

(c) generation of hydroelectricity; and

(d) industrial purposes.

The Tehri dam is situated near Tehri town in the region of Kumaon-Garhwal Himalaya in Uttarakhand, and is the highest constructed reservoir in India having a height of $260.5 \mathrm{~m}$ (Table 1). The dam creates a reservoir of 4.0 cubic kilometres with a surface area of $52 \mathrm{~km}^{2}$. The water of reservoir is primarily utilised for drinking, irrigation, generation of hydropower, and industrial purposes.

The reservoirs operation policy involved some random operational factors to fulfil various demands from different reservoir stakeholders viz., meeting irrigation demand, meeting emergent demand for power, and so on. The water that is released from the Rihand reservoir is recommended on the basis of water availability in the reservoir at the end of monsoon season, irrigation water demand of state of Bihar, and the generation of hydropower and several releases proposed by Uttar Pradesh 
Power Corporation Limited (UPPCL) (Lucknow, UP, India)/Uttar Pradesh Jal Vidyut Nigam Limited (UPJVNL) (Sonebhadra, India).

Table 1. Characteristic of the Rihand and Tehri Dam.

\begin{tabular}{|c|c|c|c|c|}
\hline Name of Dam & $\begin{array}{l}\text { Gross Storage } \\
\text { Capacity }\left(\mathbf{k m}^{3}\right)\end{array}$ & $\begin{array}{c}\text { Effective Storage } \\
\text { Capacity }\left(\mathrm{km}^{3}\right)\end{array}$ & $\begin{array}{c}\text { Dead Storage } \\
\left(\mathbf{k m}^{3}\right)\end{array}$ & $\begin{array}{c}\text { Reservoir Area } \\
\left(\mathbf{k m}^{2}\right)\end{array}$ \\
\hline Rihand & 10.6 & 8.9 & 1.7 & 466 \\
\hline Tehri & 3.54 & 2.62 & 2.8 & 52 \\
\hline
\end{tabular}

\section{Data and Methodology}

The water quantity the optimal operation model for reservoirs based on SWAT includes two segments. The first segment is the coupling of the distributed hydrologic model (SWAT) with the function of floodgates and reservoirs. This segment is the important part and is effective in estimating hydrologic deviation in the available water resources within the basin scale and specifies the essential set of conditions for the optimal reservoir function. The duration of study ranges from January 1960 to December 2014. The data employed involve the observed hydro-meteorology data for the study region, the reservoirs water levels, quantity of the generated hydropower, and surface runoff at different stations. The second segment is the optimal operation model for reservoirs, which would be employed to achieve two purposes, viz. maximizing both the hydropower potential and water resources availability. The framework in Figure 2 demonstrates the schematic figure of the approach that was adopted in this research in order to attain the objectives.

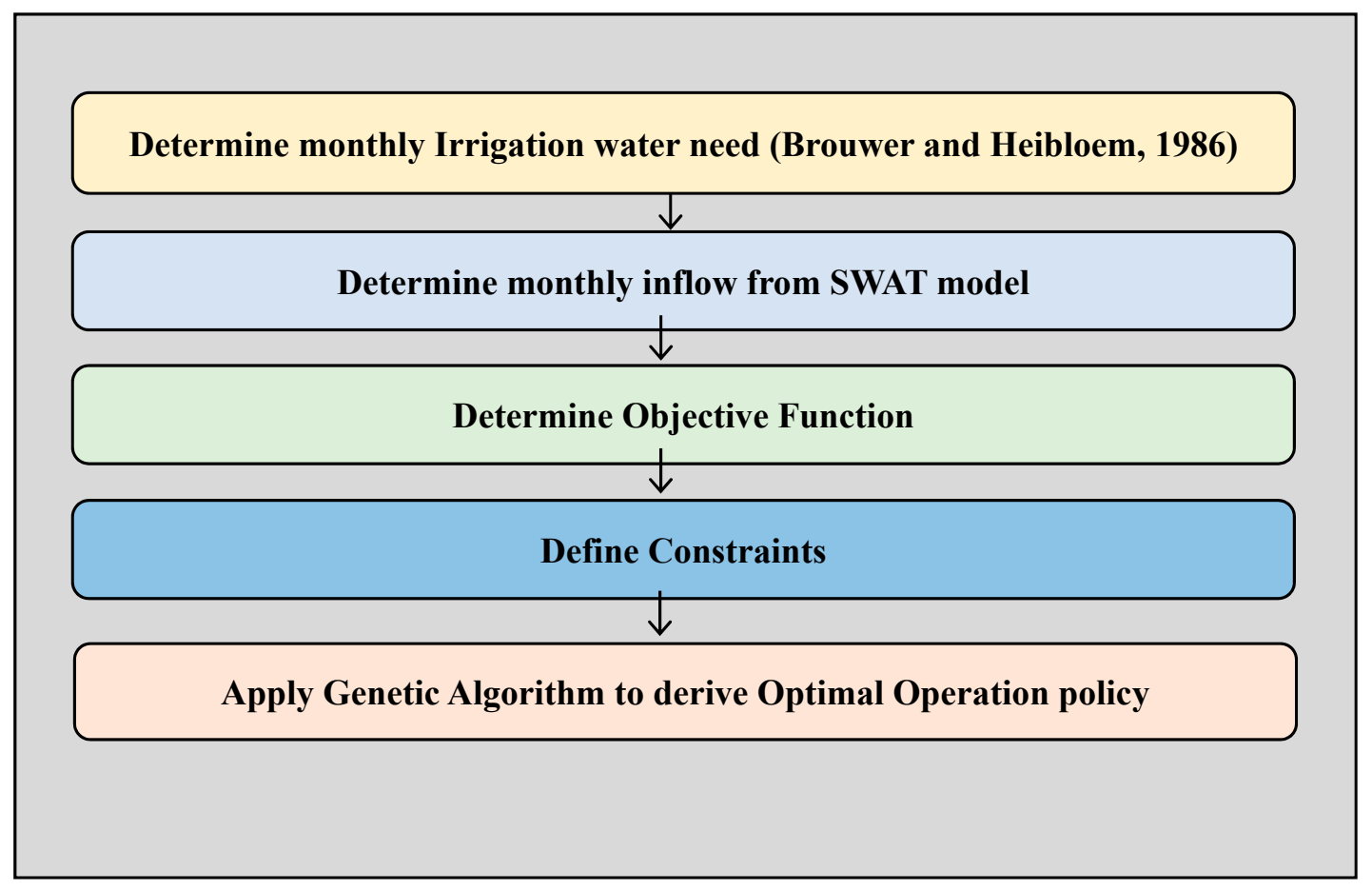

Figure 2. Schematic diagram of the methodology adopted in the study.

For enhancing the reservoirs function, the prerequisite knowledge of the total demand of water is requisite. The collective demand of water comprises of the fundamental demands (e.g., for satisfying ecological and environmental needs, sustaining navigation, etc.), industrial and domestic water needs, and irrigation water demands. For the computation of water that is needed to fulfil irrigation demand, a traditional technique for assessing water demand for crop is employed. 


\subsection{SWAT Model}

The SWAT model is a physically based semi-distributed continuous time model that is developed by the United States Department of Agriculture (USDA) to explore the effect of climate, land use changes on water, and sediment in large un-gauged basins. SWAT can operate on a large basin and is able to replicate numerous processes viz. surface runoff in rivers, sediment and so on, on a daily/sub-daily time step [72,73]. SWAT simulates several hydrologic procedures, comprising the generation of streamflow, exercising either the Green and Ampt infiltration equation or Soil Conservation Service (SCS) curve number method. For the quantification of evapotranspiration, the SWAT model offers several approaches, namely, Hargreaves, Priestley-Taylor, or Penman-Monteith methods. Groundwater flow, percolation, and lateral flow are evaluated using the mass balance of the underlying system.

SWAT model has been structured for the entire Ganga river basin [9]. The basin has been apportioned into 1045 sub- basins and 20,628 Hydrological Response Units (HRUs) employing Digital Elevation Model (DEM) data from Shuttle Radar Topographic Mission (SRTM), land cover data from National Remote Sensing Centre (NRSC), and soil attributes dataset from the Food and Agriculture Organization (FAO) [9]. The daily reanalysis and re-gridded weather data from IMD (rainfall, temperature) has been used. Daily rainfall data are at a resolution of $0.25^{\circ} \times 0.25^{\circ}$ latitude by longitude grid points, whereas temperature data are at $0.5^{\circ} \times 0.5^{\circ}$ resolution [74-76].

Various SWAT parameters that has been employed for calibration purpose, namely, Snow parameters (SMFMX, SMTMP, SMFMN, SFTMP), Elevation band parameters (PLAPS, TLAPS), and Hydrological parameters (CN2, SOL_AWC, ESCO, GW_DELAY, and GW_REVAP) [9,72,73]. The CN2 is the curve number parameter, which controls the fraction of water that infiltrates into the soil or comes as surface runoff through overland flow [72,73]. SOL_AWC is the available water capacity of the soil layer and is referred to as the plant available water [72,73]. ESCO is the soil evaporation compensation factor and it controls the soil evaporative demand that is to be met [72,73]. When the value of ESCO gets closer to 0, the model will receive more water from the lower soil level to fulfil the evaporative demand. GW_REVAP is the ground water revap coefficient, which is a SWAT term to describe the movement of water into overlying unsaturated layers as a function of water demand for ET. The GW_REVAP parameter controls the amount of water in the capillary fringe that separates the unsaturated zone and the saturated zone to move upward (to fulfill evaporative demand) [72,73]. A larger GW_REVAP value results in a larger transfer rate from the shallow aquifer to the unsaturated zone. GW_DELAY is the groundwater delay time and increase in the value of GW_DELAY, increases the time between water exits the soil profile and enters the shallow aquifer [72,73]. SMFMX and SMFMN are the melt factor for snow on 21 June and 21 December, respectively, which account for the influence of density of snow pack on snow melt. SFTMP and SMTMP are the snowfall temperature and the snow melt base temperature respectively. PLAPS and TLAPS are the precipitation lapse rate and temperature lapse rate respectively, which accounts for the change in the precipitation and temperature on account of elevation [72,73]. SWAT model simulation has been compared with the observed data at Uttarkashi and Rihand gauge stations provided by Central Water Commission (on a daily basis), employing commonly used statistical parameters (Figure 3). 


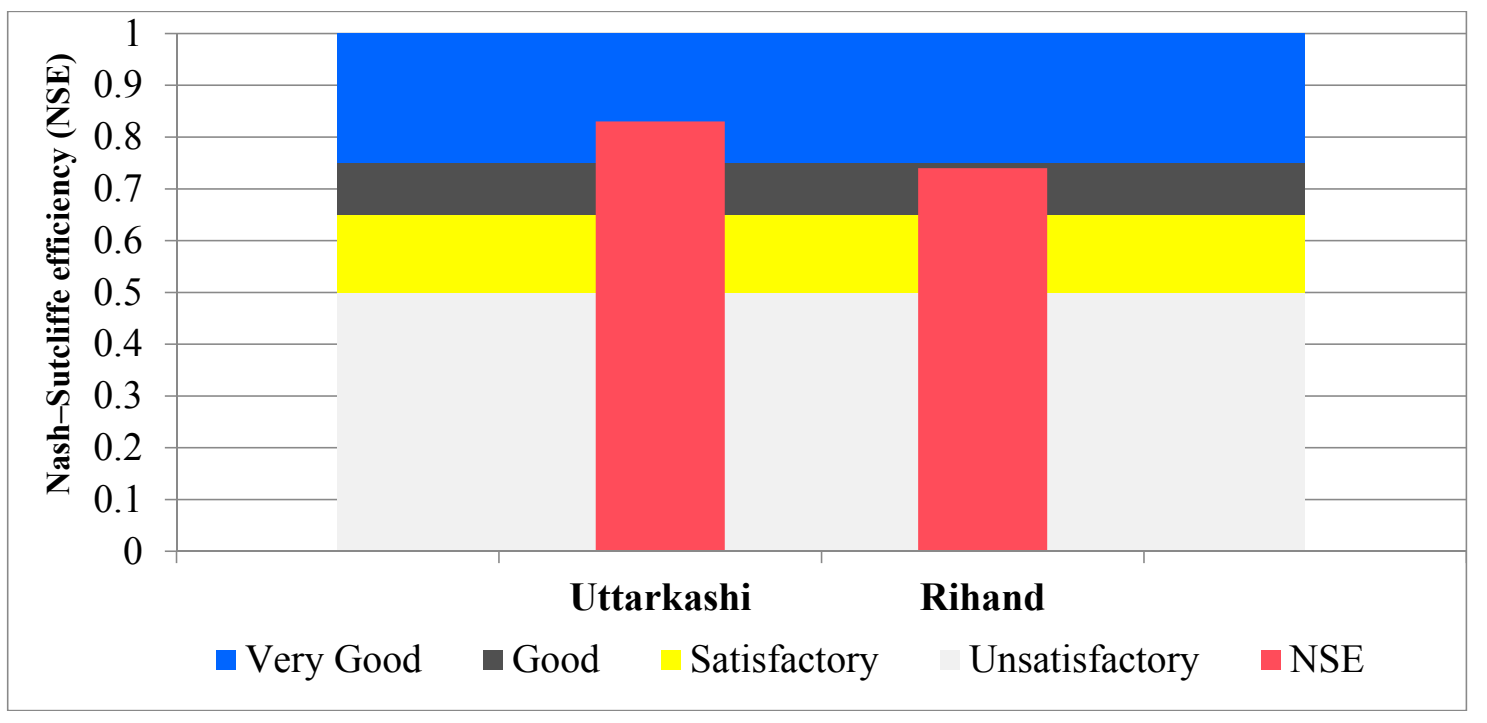

Figure 3. Nash-Sutcliffe efficiency (NSE) at Uttarkashi and Rihand Gauge Stations.

\subsection{Reservoir Inflow}

The estimation of stream flow coming to the reservoir system is the important factor; hence, the estimation of credible flows for the basin is essential. The inflow coming to reservoir is employed to compute the net irrigation demand and constructing mass balance constraint for the reservoir. Hence, the computation of credible flows for the basin by employing the SWAT model has been necessary. Reservoir inflow data for each month $t, I_{t}$, has been estimated from the calibrated and validated SWAT model [9]. The surface runoff simulated for the two reservoirs sub-basin for the 54-year period (1960-2013) has been derived from the SWAT model [9]. It should be highlighted that the simulation of SWAT model has been done at a daily time step, which is then aggregated to attain data at a monthly time step to employ in this research (Table 2).

Table 2. Analysis of Inflow for the Reservoirs simulated from the Soil and Water Assessment Tool (SWAT) model.

\begin{tabular}{|c|c|c|}
\hline & Rihand Dam $\left(\mathrm{Mm}^{3}\right)$ & Tehri Dam $\left(\mathrm{Mm}^{3}\right)$ \\
\hline January & 166.55 & 113.31 \\
\hline February & 169.43 & 64.74 \\
\hline March & 228.91 & 114.33 \\
\hline April & 215.52 & 240.14 \\
\hline May & 275.42 & 457.95 \\
\hline June & 429.32 & 822.32 \\
\hline July & 1378.92 & 1637.19 \\
\hline August & 1847.47 & 2137.63 \\
\hline September & 1356.22 & 1829.83 \\
\hline October & 495.54 & 1048.84 \\
\hline November & 333.79 & 527.30 \\
\hline December & 248.46 & 258.74 \\
\hline Annual & 7145.55 & 9252.32 \\
\hline
\end{tabular}

\subsection{Irrigation Water Demand}

The water collected in the Rihand dam irrigates about $2500 \mathrm{~km}^{2}$ of the agricultural land. The power house has the installed capacity of $300 \mathrm{MW}$.

The water that is needed to meet the irrigation demand is generally computed by utilising the methodology that was proposed by Brouwer and Heibloem, (1986) [77]. The water necessary to meet 
the irrigation demand leans upon the water demand of the crops, which has been outlined as "the amount of water required to satisfy the loss of water due to evapotranspiration $\left(\mathrm{ET}_{\text {crop }}\right)$ of a crop that is free from diseases, raising in fields under non-restricting soil conditions embracing fertility of the soil and availability of water in the soil, thus accomplishing high level of production in the specified cultivating atmosphere" [78]. Therefore, in order to compute the water that is needed to meet the irrigation demand aimed at the intended farming land, the subsequent parameters has been computed: crop evapotranspiration, reference crop evapotranspiration, net irrigation, and actual demand of water required for irrigation with attention being given to both the manner of irrigation and the efficiency of application [79].

\subsubsection{Reference Crop Evapotranspiration}

Brouwer and Heibloem, (1986) [77] proposed a methodology to compute the reference crop evapotranspiration, $E T_{0}(\mathrm{~mm} / \mathrm{mon})$, by employing the available meteorology data of temperature (Equation (1)), and the sunshine duration or radiation (Equation (1)) from Brouwer and Heibloem, (1986) [77]:

$$
E T_{0}=p\left(0.46 T_{\text {mean }}+8\right)
$$

where

$p=$ Average Daily Percentage of Yearly Daytime, $T_{\text {mean }}=\left(T_{\max }+T_{\min }\right) / 2$.

$T_{\text {mean }}=$ the mean daily temperature,

$T_{\max }=$ (Sum of all $T_{\max }$ values during the month/number of days of the month), and

$T_{\min }=$ (Sum of all $T_{\min }=$ values during the month $/$ number of days of the month).

\subsubsection{Crop Evapotranspiration}

After the estimation of reference crop evapotranspiration $\left(E T_{0}\right)$, the equation for computing crop evapotranspiration $\left(E T_{\text {crop }}\right)$ is given below:

$$
E T_{\text {crop }}=K_{\mathrm{c}} \times E T_{0}
$$

where $K_{\mathrm{c}}$ is the crop coefficient that is associated with the attributes of the crop and the stages of its growth.

\subsubsection{Net Irrigation Water Demand}

As the difference between effective rainfall and the evapotranspiration of crop has been adopted to compute the required amount of water that is needed for irrigation, it is imperative to assess the effective rainfall first. Furthermore, the effective rainfall indicates the quantity of the rainfall that gets infiltrated inside the soil and subsequently gets evapotranspirated by the crops into the air [78]. Moreover, not the entire rainfall that precipitates has been efficient, as some portion of the rainfall might be lost because of surface runoff, canopy intervention, or evaporation [78]. However, these hydrological processes could be computed by utilising physically based hydrological models (e.g., SWAT) [9]. In the present research, stream flow, lateral flow, and seepage simulated by employing the SWAT model has been adopted, and the effective rainfall could be estimated from the equation below:

$$
R_{\text {eff }}=P R E C-Q-L A T Q-S E E P
$$

where $R_{\text {eff }}$ is the effective precipitation, and PREC is rainfall reaching the surface of the soil, $Q$ is stream flow, $L A T Q$ is subsurface lateral flow (coming from the root zone and meeting the main channel), and SEEP is seepage that is coming out of the bottom of the soil profile. 
The net water needed to meet the irrigation demand, $I r_{\text {net }}$, is computed by using the following equation:

$$
I r_{\text {net }}=E T_{\text {crop }}-R_{\text {eff }}
$$

\subsubsection{Irrigation Water Demand}

The water that is needed to meet the irrigation demand has been computed based on the requirement of crop for water, effective rainfall, and the efficiency of the irrigation. To compute the irrigation water demand, an efficiency factor has been employed in order to account for the loss in the water that is incurred during the conveyance and the application on the field [78]. The efficiency generally comprises of three sections, that symbolise the loss in the water through conveyance, field canal, and field application [78]. In this study, for conveyance and canal efficiencies, the value of 0.8 has been used. While, for field application efficiency, the value of 0.6 (corresponding to furrow irrigation) has been adopted. Therefore, the final project efficiency for our study has been taken as $0.4(0.8 \times 0.8 \times 0.6)$.

\subsubsection{Estimation of Other Water Demands}

Apart from the water that is needed to meet irrigation demands, the water of the reservoirs is used to meet domestic viz. drinking and industrial demands, navigation, and the maintenance of minimum water in the downstream of the reservoir to sustain ecology, environmental, and aquatic habitat. For the present study, other demands, such as domestic and industrial demands, have been contemplated as the constant requirements. The target release for the reservoirs is deliberated to be equal to the irrigation demand, while the storage is considered to be equal to the summation of the dead storage and the other essential demands for the next three months. That is to say, that this would ensure that the three months of other necessary demands is achieved by the reservoir. The ecological streamflow for sustaining aquatic habitat is to provide the minimum streamflow regimen for aquatic. For the present study, the $10 \%$ of the annual average flow for the river that was suggested by Tenant (1976) [80] has been taken as the minimum instantaneous flow that is required to sustain short-term survival for aquatic life.

\subsection{Multi-Objective Optimization Model}

Multi-objective optimization problems for the reservoirs involve the simultaneous optimization of numerous non-commensurable and often contradictory objectives. Often, the reservoirs have two primary uses, generation of hydropower and supply sufficient quantity of water to meet irrigation demand. As can be seen that these objectives are generally contradictory and conflicting in nature with each other, an increase in the level of generation of hydroelectric power demands a higher level of water, which means a lesser amount of water releasing to meet irrigation demand. Likewise, the policy makers and decision makers should consider the probable trade-off between maximizing generation of hydroelectric power and gratifying irrigation and navigation requirements before reaching out for the most optimal policy.

\subsection{Genetic Algorithm Model Formulation}

Genetic Algorithms (GAs), as proposed by John Holland [57,58], are a section of evolutionary algorithms (EAs), which mimic courses that are observed in natural evolution to optimize a certain objective function $[43,81,82]$. GAs, analogous to Darwinian natural selection, is a search technique centred around the methodology of natural selection, evolution, and natural genetics, through generations in an endeavour to obtain an optimal solution.

GA lets a gamut comprised of different entities (solution points) and steered random searches to evolve under stated selection policies to the point, which maximizes/minimizes the considered objective problem $[57,58]$. Similar to the other EAs, no derivatives are required by GAs to assess the best 
solutions. GAs could also be employed to accomplish both local and global investigation within a big search space $[43,83]$. The fundamentals that are necessary for GAs to commence are the representation of parameter that is needed to be maximised, the genetic operator, and the objective function. The decision variables that are necessary for the problem of optimization has been programmed to a single artificial gene within the whole GA set, which can be outlined as one of the many likely answers for the given optimisation problem. The aptness of a chromosome to be considered as a prime solution to a certain optimisation problem is relied upon the degree of the objective function that is represented by it, in order to assess the likelihood of existence. The investigation of GA begins with an arbitrarily generated population of chromosomes initially, and is then combined through genetic operators, namely selection, crossover, and mutation, to refine the assessment of solutions by generating fitter chromosomes through iterations. The selection process is essentially to select chromosomes in the gene pool with a superior fitness values for survival or generating offspring within the population of the subsequent production. Following the evaluation of fitness function, selection has been accomplished via roulette wheel selection [58], which is analogous to the essential tool of the "Survival of the fittest", to form the next generation, with every portion of a roulette wheel being fragmented to fitness values. Therefore, the strings having higher fitness value would possess a greater possibility of being transferred to the next generation. The information of the two likely solutions of the given optimisation problem is reciprocated through crossover between two random positions. Single-point crossover or multi-point crossover is elected randomly. Mutation is a key method, which allows for the introduction of new genetic chromosome to a population. Mutation allows for the modification of a string to a stipulated extent, which could be both negative or positive. Following the mutation, the function's fitness is again computed to obtain the prime solution for the particular set of decision variables.

\subsection{Genetic Algorithm Model Development}

In the present study, the primary aims of the optimization of reservoir model are to minimalize the deficit of water supply, and to maximize the generation of hydroelectric power. The aforementioned objectives of the optimisation problem are mutually conflicting/competitive, as hydropower generation demands higher head in the reservoir to maximize power production and subsequently generate more energy. However, supply of water to meet irrigation and other demands necessitates release of water to meet these demands.

For the present study, three scenarios coupled with three conditions of priority has been devised to simulate the model optimization. For the first scenario, the objective function is to minimize the deficit of water supply only, designated as the supply priority scenario. Whereas for the second scenario, designated as the power priority the objective function is maximization of generation of hydropower only. While the third scenario intents to maximize the advantages of both supply priority scenario and the power priority scenario simultaneously. Therefore, while the first two scenarios have been intended to regulate the reservoir with a specific and solitary objective, the third scenario involves two conflicting/competitive goals having equal priorities. However, basic water demand must be met to warrant the river's environmental well-being, irrespective of the three scenarios. The genetic algorithm toolbox in MATLAB has been used to design the optimal operating policies for managing water reservoir systems. MATLAB has been utilised due to its ability to provide numerous built in auxiliary functions is helpful in function optimization, is totally portable, and it is methodical in numerical computations.

\subsubsection{Objective Function for Rihand Dam and Tehri Dam}

In this study, the objective function for the proposed GA model (the fitness function) for the Rihand Dam and Tehri Dam is minimalizing the squared deviation of monthly demand for irrigation deficit and the aberration in the objective storage and maximization of hydropower generation. The following 
equation represents the mathematical equation of the optimization model: To minimalize the deficit in supply of water;

$$
\text { Minimize } S Q D V=\sum_{t=1}^{12}\left[\left(R_{t}-D_{t}\right)^{2}-\left(S_{t}-S_{T}\right)^{2}\right]
$$

where, $D_{t}=$ water demand for irrigation during the month " $t$ ', $R_{t}=$ release of water to irrigation demand during the month " $t$ ", $S_{T}=$ target storage in $\mathrm{Mm}^{3}$, and $S_{t}=$ initial storage during the month " $t$ ".

To maximize the energy production, the following equation represents the mathematical equation of the optimization model:

$$
\text { Maximize } E=\sum_{t=1}^{12} p\left(R_{t} H_{t}\right)
$$

where $E$ is the overall energy generated in $\mathrm{M} \mathrm{kWh}$ (million $\mathrm{kWh}$ ); $p$ is the coefficient of power generation; $R_{t}$ is the total discharge into the riverbed turbine during the period $t$ in $\mathrm{Mm}^{3}$; and,$H_{t}$ are the net head available to turbine in meters in period $t$.

The optimization of the reservoir optimization problem has been subjected to the subsequent constraints:

\subsubsection{Constraints}

The solution of the multiobjective optimisation problem is constrained by several restrictions that are imposed on the decision variable. Constraints may define the gamut of the defined objective function, or on the other hand, can add restrictions on the solution for a given problem.

\section{Mass Balance Constraint}

The correlation between the month to month storage is driven through the equation of continuity. The equation of continuity has been specified as,

$$
S_{t+1}=S_{t}+Q_{t}-R_{t}-E_{t}-O_{t}, t=1,2,3, \ldots, 12
$$

where, $Q_{t}=$ inflow in the reservoir for the month " $t$ ", $S_{t+1}=$ final storage of the reservoir for the month " $t$ ", $E_{t}=$ Loss due to evaporation from the reservoir for the time period " $t$ ", and $O_{t}=$ Overflow for the reservoir during month " $t$ ".

\section{Release Constraint}

The water that is released for the irrigation purpose during the contemplated month ought to be equal or less than the net demand of irrigation during the stated month and this constraint is represented by the following equation,

$$
R_{t} \leq D_{t}, t=1,2,3, \ldots, 12
$$

Storage Limits

The storage of the reservoir during any month must never be larger than the underlined reservoir capacity, and it must never be lower than the defined reservoir dead storage. Arithmetically, the constraint has been represented by the following equation:

$$
S_{\min } \leq S_{t} \leq S_{\max } \text {, for all } t=1,2,3, \ldots, 12
$$

\section{Over Flow Constraint}

Over flow constraint manages the condition, once the final storage surpasses the maximum defined limit of the reservoir. Mathematically, the constraint is represented by the following equation:

$$
O_{t}=S_{t+1}-S_{\max }, t=1,2,3, \ldots, 12
$$


and

$$
O_{t} \geq 0, t=1,2,3, \ldots, 12
$$

Maximum Power Production Limits

$$
p R_{t} H_{t} \leq E, t=1,2,3, \ldots, 12
$$

where, $E$ is the maximum quantity of hydropower in $\mathrm{M} \mathrm{kWh}$ (million $\mathrm{kWh}$ ) that could be generated; $p$ is coefficient of power production; $R_{t}$ is the discharge into the riverbed turbine for the period $t$ in $\mathrm{Mm}^{3}$; and, $H_{t}$ are the net head that are available to turbine in meters during period $t$.

\section{Results and Discussion}

The reservoir optimization/simulation model that is characterised by Equations (5)-(12) is adopted in the Rihand Dam, and Tehri Dam to obtain the operative policies for simultaneously optimizing several objectives of the generation of hydropower and the supply of water. In the present study of the GA model, stream flow coming into the reservoir system on a monthly basis, and, the monthly demands for irrigation purposes are the two critical input variables. The primary goal has been to estimate the amount of water that is needed to be released to satisfy the overall demand. That is to say that the objective function for the optimisation of reservoir depends upon the releases from the reservoir at every time step, therefore, water discharges must be the decision variable whereupon the GA revolves around. Additionally, the single variable that is unknown in the optimisation of reservoir operation model is the target storage $\left(S_{t}\right)$, and it is computed by applying the GA for every month to minimalize the deficit of supply of water and the maximization of hydropower generation.

For the present study, three scenarios coupled with three conditions of priority (namely, supply priority, power priority, and equal priority) have been devised to simulate the model optimization. Employing the aforementioned three optimisation scenarios and the GA optimization technique, the stipulated reservoir storages are accomplished for the different operating policies.

Figures 4 and 5 pictures the associated target reservoir storage. From Figures 4 and 5, it has been noted that, to meet the demand in the first scenario (supply priority), it requires larger water release from the Rihand and Tehri dam, and consequently lower water level, resulting in the smallest attained final storages. On the other hand, the second scenario demands the impounding of water inside the reservoir at a higher stage to achieve added head and thus generating more energy. That is to say, the reservoir managers and associated authority are inclined to hold the water in the reservoir, subsequently ensuring the highest attained target storages. It can be noted that releases for the purpose of irrigation has reduced considerably in this scenario. Nevertheless, for the scenario of equal priority, the target storages that were achieved after optimized are in between the two scenarios. Although the derived operating rule curves for the reservoirs for three different scenarios serve distinctive objectives, in spite of that, the constraint ensuring that the attainment of basic surface runoff demands enumerated in the reservoir optimization model, can ensure the minimum streamflow in the river, and thus, should be able to warrant the river's environmental health. The other possible and optional operational, storage, and release policies would be able to support the reservoir authority and policy makers in formulating an efficient and sustainable guideline for several conflicting/competing priorities rendered and for diverse inflow scenarios. The approach of multi-objective GA has been thus very much beneficial, in fabricating a set of well-defined solution for the objectives, which are contradictory/conflicting and would ultimately serve for better operation involving a small time of computation.

The average monthly results of reservoir storage that were obtained by the genetic algorithm and historical operations are shown in Figures 4 and 5. It demonstrates that (1) the maximum storage volumes for both the reservoirs for all the three priority scenarios are much smaller than those of 
historical operations, thus providing enough water in the river to warrant river health; (2) most of the storage volumes obtained from the GA for the supply priority are close to the average value for the historical operations and much greater than the lowest values, thus providing more water to meet irrigation demand; (3) for the power priority scenario, the storage volumes are close to the maximum value for the historical operations. In summary, the results based on optimal solutions that are computed by GA and historical operations implies that by means of the GA optimisation approach, both the water demand and the generation of hydropower could be optimised and should not cause any significant shortage of water in most of the years (Figures 4 and 5).

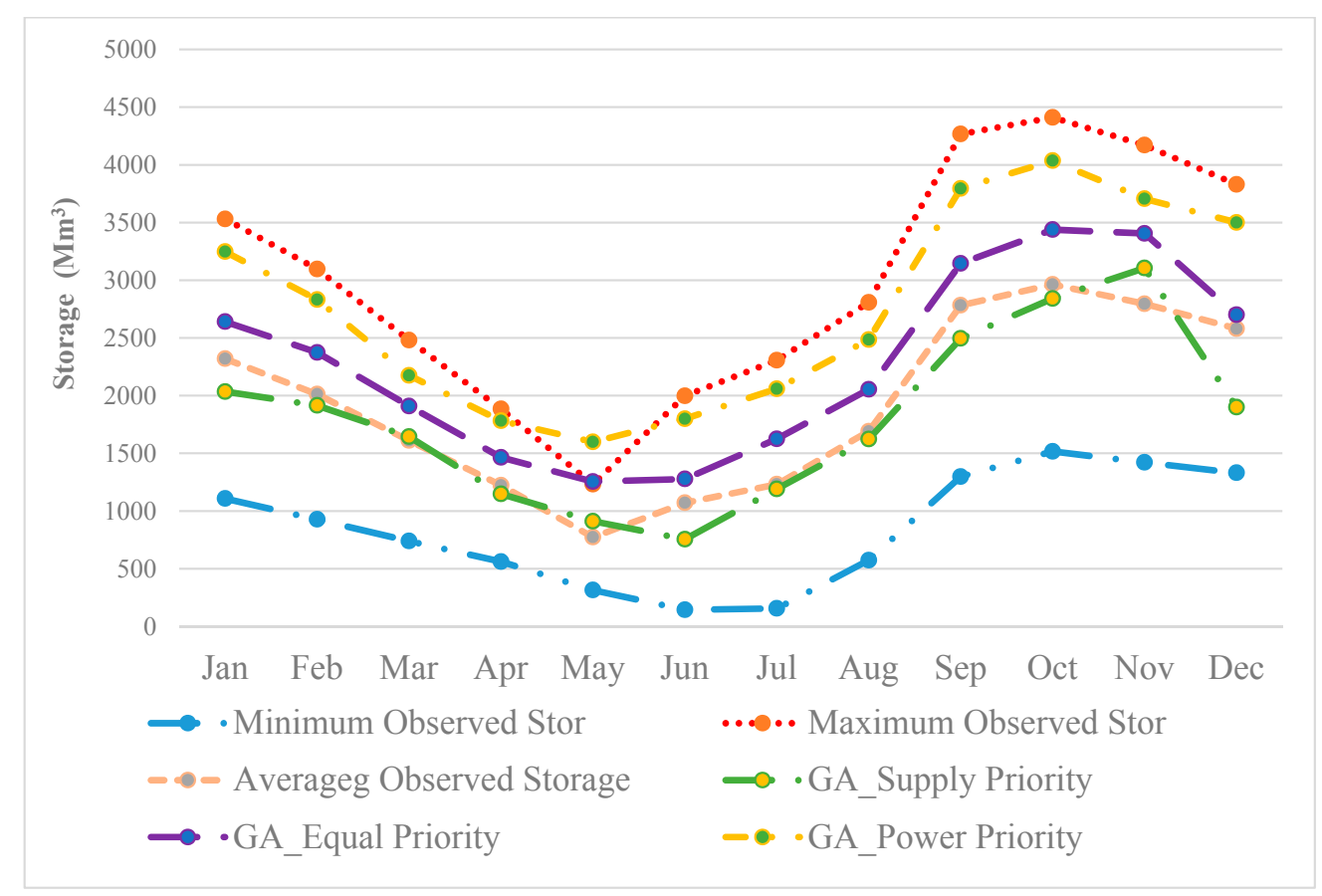

Figure 4. Target Storage for Rihand Dam for three scenarios.

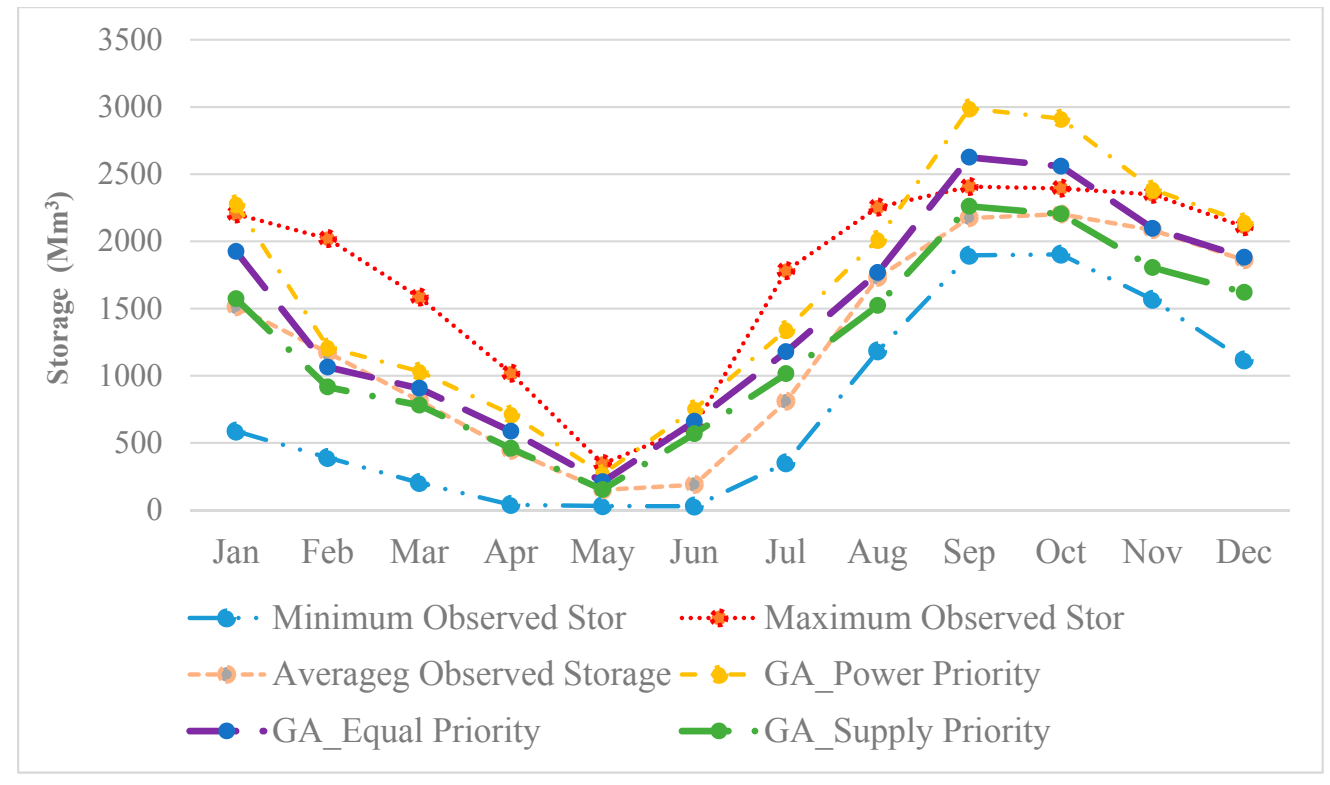

Figure 5. Target Storage for Tehri Dam for three scenarios. 
Based on the hydrologic modelling using SWAT and Genetic Algorithm, this study provides reasonable operating policies for the two important reservoirs for the basin. Moreover, the optimized results that were obtained should be competent in delivering better operation choices in response to wet and dry circumstances in water supply. Whenever a drought condition has been anticipated in the coming future, the storage-governed priority measure should be able to strengthen the potential of the reservoir to take care of the emergent requirements of water or prospective water lend. The reservoirs concerned might be holding a greater volume of water by cutting out the release quantity for certain dates, however complementing on other days. The higher storage volume should be able to achieve developing drought-response jobs. However, if the available water is above average and no scarcities have been anticipated, hydropower generation-governed priority results in the added generation of hydropower $[23,28]$. The increase in the production of environmental friendly energy from hydropower sectors can also help in mitigating the greenhouse gas emitted from the power supply from thermal power plants and different sources of energy can be substituted by the additional hydro-power generation. Nevertheless, the third scenario of equal priority can be adopted, as both of the approaches for the mitigation of drought and satisfying irrigation demand and increased hydropower generation become important. Several studies have investigated the optimal reservoir operating rules for the reservoirs using genetic algorithm $[16,30,31]$ and have advocated that the optimal reservoir policies that were obtained by employing the genetic algorithm should be better than the currently employed random operational policy for both meeting total water demand for the irrigation purposes and maximizing the annual production of hydropower.

Nowadays, with the rapid growth in the population, and consequently, the increase in the demands, the ecological health of the river and the shortage of water supply have progressively developed into a prominent problem and thus, have been able to attract the concerns of both government and the public. Predominantly, the revamp of the operating policies of the reservoirs could influence the way in which the reservoirs are being operated to meet the demands. However, added unforeseen and serious complications, such as mitigating flood, might stop the reservoir operators from attaining the desired target or final storages. Yet, the endeavour to accomplish the optimal operating policies should help in warranting the sustainability of river ecosystem and diminish water supply deficit, while undertaking hydropower generation and serving added demands. Hence, the optimal final storage that was obtained in this research may provide decision makers and reservoir operators with informative and valuable information that is needed for efficient operation of the Rihand and Tehri reservoir.

\section{Summary and Conclusions}

The conventional optimization model offers merely single optimal solution in a particular simulation, and applies a preference vector that necessitates extremely careful alterations to attain the optimal solutions. Nevertheless, the Multi-objective Genetic Algorithm could attain non-dominated solutions to multi-objective problems in a single simulation employing the population-by-population methodology. Genetic algorithms propose a dominant optimization methodology and have popularly established itself in reservoir operation planning and management; however, rising numbers of variables demands large amount of computation, and ends in a very time-consuming evolution amid successive generations, therefore abruptly reducing the likelihood of converging into an optimum solution. In addition, the efficacy and effectiveness of the solution does not depend on a function that is outlined by the operator and decision makers, subsequently these objective functions could be employed precisely without demanding any transformations.

Evolutionary computation methods exhibit huge prospective in optimizing complicated problems. In this research, a Multi-Objective GA approach has been successfully employed for the problem of the optimization of the operation of the multi-objective reservoir. The foremost benefit of the Multi-Objective Genetic Algorithm methodology is its ability in able to discover several pareto optimal solutions in a particular simulation, which has been both efficient and effective at the same time 
and it supports the operators and decision makers to make fitting assessments and decisions in diverse situations. This research suggests a constrained genetic algorithm for the planning and management of multi-purpose reservoir, which includes the meeting of human requirement and the generation of hydropower requirements. A multi-objective model has been articulated by incorporating hydropower and irrigation as the two conflicting/competing objectives and the multi-objective reservoir optimization model, exercising a combination of the SWAT simulation model and Genetic Optimisation Algorithm, has been applied to develop efficient operation policies for the Rihand reservoir system and the Tehri Reservoir system, in India, in order to minimalize the annual sum of squared deviation of release to meet irrigation demand and target storage, and to maximize the reservoir capacity to generate hydropower. The operating policies of reservoirs (i.e., final storage) conforming to the three priority situations (supply of water only, hydropower generation only, and equal priority) have been developed. Under the new operation policy, optimised by GA, the trade-off concerning meeting the irrigation and other demands and generation of hydropower has been resolved. An optimal solution has been determined, which is proficient enough in sufficing the numerous demands and generation of hydropower, as compared to the contemporary procedures. The balanced optimum solution could uphold a higher level of water in the reservoir, and at the same time, meet the several downstream demands. Additionally, the optimised policy may amplify the generation of hydropower during the flood season, as well as increase the likelihood of accessibility of water for the subsequent dry season. In this study, optimal solutions for the regulations reservoir have been accomplished. The assessment of the results implies that the operation of the reservoir for hydropower generation and water supply can be enhanced considerably. The optimization model that was proposed for the two reservoirs system has been robust and adaptable in serving multi-objectives under different priorities. Thus, this research has been successfully able to exhibit the efficiency and the effectiveness of Multi-Objective Genetic Algorithm for varying multi-objective reservoir operation strategies. It has been exhibited that the technique has been efficient in optimising the rule curves managing the operation of the reservoirs in a multi-objective framework.

Author Contributions: Conceptualization, J.A., A.K.G. and R.K.; Methodology, J.A., A.K.G. and R.K.; Software, J.A.; Validation, J.A., A.K.G. and R.K.; Formal Analysis, J.A.; Investigation, J.A.; Resources, J.A.; Data Curation, J.A.; Writing-Original Draft Preparation, J.A.; Writing-Review \& Editing, J.A., A.K.G. and R.K.; Visualization, J.A., A.K.G. and R.K.; Supervision, J.A., A.K.G. and R.K.

Acknowledgments: The authors would like to thank Indian Institute of Technology Delhi (India) for providing support for conducting this study. We appreciate the data support from the Central Water Commission (http: $/ /$ www.cwc.nic.in/ ) and also from the Indian Meteorological Department (IMD). We also thank the editor and two anonymous reviewers for their invaluable comments.

Conflicts of Interest: The authors declare that they have no conflict of interest.

\section{References}

1. Brown, C.M.; Lund, J.R.; Cai, X.; Reed, P.M.; Zagona, E.A.; Ostfeld, A.; Hall, J.; Characklis, G.W.; Yu, W.; Brekke, L. The future of water resources systems analysis: Toward a scientific framework for sustainable water management. Water Resour. Res. 2015, 51, 6110-6124. [CrossRef]

2. Davies, E.G.R.; Simonovic, S.P. Global water resources modeling with an integrated model of the social-economic-environmental system. Adv. Water Resour. 2011, 34, 684-700. [CrossRef]

3. Rockström, J.; Karlberg, L.; Wani, S.P.; Barron, J.; Hatibu, N.; Oweis, T.; Bruggeman, A.; Farahani, J.; Qiang, Z. Managing water in rainfed agriculture-The need for a paradigm shift. Agric. Water Manag. 2010, 97, 543-550. [CrossRef]

4. Franczyk, J.; Chang, H. The effects of climate change and urbanization on the runoff of the Rock Creek basin in the Portland metropolitan area, Oregon, USA. Hydrol. Process. 2009, 23, 805-815. [CrossRef]

5. IPCC. Climate Change 2014. Impacts, Adaptation, and Vulnerability Part A: Global And Sectoral Aspects; IPCC: Geneva, Switzerland, 2014; Volume 53. 
6. Zhang, A.; Zhang, C.; Fu, G.; Wang, B.; Bao, Z.; Zheng, H. Assessments of Impacts of Climate Change and Human Activities on Runoff with SWAT for the Huifa River Basin, Northeast China. Water Resour. Manag. 2012, 26, 2199-2217. [CrossRef]

7. Mishra, A.; Singh, R.; Raghuwanshi, N.S.; Chatterjee, C.; Froebrich, J. Science of the Total Environment Spatial variability of climate change impacts on yield of rice and wheat in the Indian Ganga Basin. Sci. Total Environ. 2013. [CrossRef]

8. Narula, K.K.; Gosain, A.K. Modeling hydrology, groundwater recharge and non-point nitrate loadings in the Himalayan Upper Yamuna basin. Sci. Total Environ. 2013, 468-469, S102-S116. [CrossRef] [PubMed]

9. Anand, J.; Gosain, A.K.; Khosa, R.; Srinivasan, R. Regional scale hydrologic modeling for prediction of water balance, analysis of trends in stream flow and variations in stream flow: The case study of the Ganga River basin. J. Hydrol. Reg. Stud. 2018, 16, 32-53. [CrossRef]

10. Wang, K.W.; Chang, L.C.; Chang, F.J. Multi-tier interactive genetic algorithms for the optimization of long-term reservoir operation. Adv. Water Resour. 2011, 34, 1343-1351. [CrossRef]

11. Yeh, W.W.-G. Reservoir Management and Operations Models. Water Resour. Res. 1985, 21, 1797-1818. [CrossRef]

12. Kadigi, R.M.J.; Mdoe, N.S.Y.; Ashimogo, G.C.; Morardet, S. Water for irrigation or hydropower generation?-Complex questions regarding water allocation in Tanzania. Agric. Water Manag. 2008, 95, 984-992. [CrossRef]

13. Nicklow, J.; Reed, P.; Savic, D.; Dessalegne, T.; Harrell, L.; Chan-Hilton, A.; Karamouz, M.; Minsker, B.; Ostfeld, A.; Singh, A.; et al. State of the Art for Genetic Algorithms and Beyond in Water Resources Planning and Management. J. Water Resour. Plan. Manag. 2010, 136, 412-432. [CrossRef]

14. Kim, T.; Heo, J.-H.; Jeong, C.-S. Multireservoir system optimization in the Han River basin using multi-objective genetic algorithms. Hydrol. Process. 2006, 20, 2057-2075. [CrossRef]

15. Bozorg-Haddad, O.; Janbaz, M.; Loáiciga, H.A. Application of the gravity search algorithm to multi-reservoir operation optimization. Adv. Water Resour. 2016, 98, 173-185. [CrossRef]

16. Wu, Y.; Chen, J. Estimating irrigation water demand using an improved method and optimizing reservoir operation for water supply and hydropower generation: A case study of the Xinfengjiang reservoir in southern China. Agric. Water Manag. 2013, 116, 110-121. [CrossRef]

17. Chang, L.C. Guiding rational reservoir flood operation using penalty-type genetic algorithm. J. Hydrol. 2008, 354, 65-74. [CrossRef]

18. Chang, F.-J.; Chen, L.; Chang, L.-C. Optimizing the reservoir operating rule curves by genetic algorithms. Hydrol. Process. 2005, 19, 2277-2289. [CrossRef]

19. Momtahen, S.; Dariane, A.B. Direct Search Approaches Using Genetic Algorithms for Optimization of Water Reservoir Operating Policies. J. Water Resour. Plan. Manag. 2007, 133, 202-209. [CrossRef]

20. Lerma, N.; Paredes-Arquiola, J.; Andreu, J.; Solera, A.; Sechi, G.M. Assessment of evolutionary algorithms for optimal operating rules design in real Water Resource Systems. Environ. Model. Softw. 2014, 69. [CrossRef]

21. Jian-Xia, C.; Qiang, H.; Yi-min, W. Genetic Algorithms for Optimal Reservoir Dispatching. Water Resour. Manag. 2005, 19, 321-331. [CrossRef]

22. Chou, F.N.F.; Wu, C.W. Stage-wise optimizing operating rules for flood control in a multi-purpose reservoir. J. Hydrol. 2015, 521, 245-260. [CrossRef]

23. Yang, T.; Gao, X.; Sellars, S.L.; Sorooshian, S. Improving the multi-objective evolutionary optimization algorithm for hydropower reservoir operations in the California Oroville-Thermalito complex. Environ. Model. Softw. 2015, 69, 262-279. [CrossRef]

24. Chung, E.-S.; Lee, K.S. Prioritization of water management for sustainability using hydrologic simulation model and multicriteria decision making techniques. J. Environ. Manag. 2009, 90, 1502-1511. [CrossRef] [PubMed]

25. Li, Y.P.; Huang, G.H.; Nie, S.L. Optimization of regional economic and environmental systems under fuzzy and random uncertainties. J. Environ. Manag. 2011, 92, 2010-2020. [CrossRef] [PubMed]

26. Matrosov, E.S.; Huskova, I.; Kasprzyk, J.R.; Harou, J.J.; Lambert, C.; Reed, P.M. Many-objective optimization and visual analytics reveal key trade-offs for London's water supply. J. Hydrol. 2015, 531, 1040-1053. [CrossRef]

27. Le Ngo, L.; Madsen, H.; Rosbjerg, D. Simulation and optimisation modelling approach for operation of the Hoa Binh reservoir, Vietnam. J. Hydrol. 2007, 336, 269-281. [CrossRef] 
28. Zhang, Y.; Xia, J.; Chen, J.; Zhang, M. Water quantity and quality optimization modeling of dams operation based on SWAT in Wenyu River Catchment, China. Environ. Monit. Assess. 2011, 173, 409-430. [CrossRef] [PubMed]

29. Khan, N.M.; Tingsanchali, T. Optimization and simulation of reservoir operation with sediment evacuation: A case study of the Tarbela Dam, Pakistan. Hydrol. Process. 2008, 2274, 2267-2274. [CrossRef]

30. Jothiprakash, V.; Shanthi, G. Single Reservoir Operating Policies Using Genetic Algorithm. Water Resour. Manag. 2006, 20, 917-929. [CrossRef]

31. Reddy, M.J.; Kumar, D.N. Optimal reservoir operation using multi-objective evolutionary algorithm. Water Resour. Manag. 2006, 20, 861-878. [CrossRef]

32. Loucks, D.P.; van Beek, E. Water Resource Systems Planning and Management; Springer: Berlin, Germany, 2017; ISBN 978-3-319-44232-7.

33. Chang, L.C.; Chang, F.J.; Wang, K.W.; Dai, S.Y. Constrained genetic algorithms for optimizing multi-use reservoir operation. J. Hydrol. 2010, 390, 66-74. [CrossRef]

34. Chang, L.C.; Chang, F.J. Multi-objective evolutionary algorithm for operating parallel reservoir system. J. Hydrol. 2009, 377, 12-20. [CrossRef]

35. Wei, C.C.; Hsu, N.S. Optimal tree-based release rules for real-time flood control operations on a multipurpose multireservoir system. J. Hydrol. 2009, 365, 213-224. [CrossRef]

36. Ndiritu, J.; Odiyo, J.; Makungo, R.; Mwaka, B.; Mthethwa, N.; Ntuli, C.; Andanje, A. Development of probabilistic operating rules for Hluhluwe Dam, South Africa. Phys. Chem. Earth 2017, 100, 343-352. [CrossRef]

37. Wardlaw, R.; Sharif, M. Evaluation of Genetic Algorithms for Optimal Reservoir System Operation. J. Water Resour. Plan. Manag. 1999, 125, 25-33. [CrossRef]

38. Wurbs, R.A. Reservoir-System Simulation and Optimization Models. J. Water Resour. Plan. Manag. 1993, 119, 455-472. [CrossRef]

39. Bashiri-Atrabi, H.; Qaderi, K.; Rheinheimer, D.E.; Sharifi, E. Application of Harmony Search Algorithm to Reservoir Operation Optimization. Water Resour. Manag. 2015, 29. [CrossRef]

40. Lund, J.R.; Ferreira, I. Operating Rule Optimization for Missouri River Reservoir System. J. Water Resour. Plan. Manag. 1996, 122, 287-295. [CrossRef]

41. Kumphon, B. Genetic Algorithms for Multi-objective Optimization: Application to a Multi-reservoir System in the Chi River Basin, Thailand. Water Resour. Manag. 2013, 27, 4369-4378. [CrossRef]

42. Ahmad, A.; El-Shafie, A.; Razali, S.F.M.; Mohamad, Z.S. Reservoir Optimization in Water Resources: A Review. Water Resour. Manag. 2014, 28, 3391-3405. [CrossRef]

43. Kaini, P.; Artita, K.; Nicklow, J. Optimizing Structural Best Management Practices Using SWAT and Genetic Algorithm to Improve Water Quality Goals. Water Resour. Manag. 2012, 26, 1827-1845. [CrossRef]

44. Labadie, J.W. Optimal Operation of Multireservoir Systems: State-of-the-Art Review. J. Water Resour. Plan. Manag. 2004, 130, 93-111. [CrossRef]

45. Madani, K.; Lund, J.R. A Monte-Carlo game theoretic approach for Multi-Criteria Decision Making under uncertainty. Adv. Water Resour. 2011, 34, 607-616. [CrossRef]

46. Chaves, P.; Chang, F.-J. Intelligent reservoir operation system based on evolving artificial neural networks. Adv. Water Resour. 2008, 31, 926-936. [CrossRef]

47. Hınçal, O.; Altan-Sakarya, A.B.; Metin Ger, A. Optimization of Multireservoir Systems by Genetic Algorithm. Water Resour. Manag. 2011, 25, 1465-1487. [CrossRef]

48. Cai, X.; McKinney, D.C.; Lasdon, L.S. A framework for sustainability analysis in water resources management and application to the Syr Darya Basin. Water Resour. Res. 2002, 38. [CrossRef]

49. Duckstein, L.; Opricovic, S. Multiobjective optimization in river basin development. Water Resour. Res. 1980, 16, 14. [CrossRef]

50. Cai, X.; McKinney, D.C.; Lasdon, L.S. Solving nonlinear water management models using a combined genetic algorithm and linear programming approach. Adv. Water Resour. 2001, 24, 667-676. [CrossRef]

51. Qi, W.; Zhang, C.; Fu, G.; Zhou, H. Quantifying dynamic sensitivity of optimization algorithm parameters to improve hydrological model calibration. J. Hydrol. 2016, 533, 213-223. [CrossRef]

52. Huang, X.; Liao, W.; Lei, X.; Jia, Y.; Wang, Y.; Wang, X.; Jiang, Y.; Wang, H. Parameter optimization of distributed hydrological model with a modified dynamically dimensioned search algorithm. Environ. Model. Softw. 2014, 52, 98-110. [CrossRef] 
53. Van Griensven, A.; Meixner, T. A global and efficient multi-objective auto-calibration and uncertainty estimation method for water quality catchment models. J. Hydroinform. 2007, 9, 277. [CrossRef]

54. Abraham, A.; Jain, L. Evolutionary Multiobjective Optimization; Springer: London, UK, 2005; ISBN 1852335831.

55. Guo, Y.; Walters, G.; Savic, D. Optimal design of storm sewer networks: Past, present and future. Integr. Assess. Decis. Support 2008, 1, 1-10.

56. Goldberg, D.E.; Kuo, C.H. Genetic Algorithms in Pipeline Optimization. J. Comput. Civ. Eng. 1987, 1, $128-141$. [CrossRef]

57. Holland, J.H. Adaptation in Natural and Artificial Systems: An introductory Analysis with Applications to Biology, Control and Artificial Intelligence; MIT Press: Cambridge, MA, USA, 1975.

58. Goldberg, D.E. Genetic Algorithms in Search, Optimization \& Machine Learning; Springer: Berlin, Germany, 1989.

59. Ahmed, J.A.; Sarma, A.K. Genetic algorithm for optimal operating policy of a multipurpose reservoir. Water Resour. Manag. 2005, 19, 145-161. [CrossRef]

60. Oliveira, R.; Loucks, D.P. Operating rules for multireservoir systems. Water Resour. Res. 1997, 33, 839-852. [CrossRef]

61. Yuan, X.; Zhang, Y.; Wang, L.; Yuan, Y. An enhanced differential evolution algorithm for daily optimal hydro generation scheduling. Comput. Math. Appl. 2008, 55, 2458-2468. [CrossRef]

62. Hakimi-Asiabar, M.; Ghodsypour, S.H.; Kerachian, R. Deriving operating policies for multi-objective reservoir systems: Application of Self-Learning Genetic Algorithm. Appl. Soft Comput. J. 2010, 10, 1151-1163. [CrossRef]

63. Cheng, C.-T.; Wang, W.-C.; Xu, D.-M.; Chau, K.W. Optimizing Hydropower Reservoir Operation Using Hybrid Genetic Algorithm and Chaos. Water Resour. Manag. 2008, 22, 895-909. [CrossRef]

64. Reddy, M.J.; Kumar, D.N. Multiobjective Differential Evolution with Application to Reservoir System Optimization. J. Comput. Civ. Eng. 2007, 21, 136-146. [CrossRef]

65. Chawla, I.; Mujumdar, P.P. Isolating the impacts of land use and climate change on streamflow. Hydrol. Earth Syst. Sci. 2015, 19, 3633-3651. [CrossRef]

66. Barik, B.; Ghosh, S.; Sahana, A.S.; Pathak, A.; Sekhar, M. Water Food Energy Nexus: Changing Scenarios in India during recent Decades. Hydrol. Earth Syst. Sci. Discuss. 2016, 1-30. [CrossRef]

67. Chung, S.W.; Ko, I.H.; Kim, Y.K. Effect of reservoir flushing on downstream river water quality. J. Environ. Manag. 2008, 86, 139-147. [CrossRef] [PubMed]

68. Fukunaga, D.C.; Cecílio, R.A.; Zanetti, S.S.; Oliveira, L.T.; Caiado, M.A.C. Application of the SWAT hydrologic model to a tropical watershed at Brazil. CATENA 2015, 125, 206-213. [CrossRef]

69. Futter, M.N.; Whitehead, P.G.; Sarkar, S.; Rodda, H.; Crossman, J. Rainfall runoff modelling of the Upper Ganga and Brahmaputra basins using PERSiST. Environ. Sci. Process. Impacts 2015, 17, 1070-1081. [CrossRef] [PubMed]

70. Sahoo, G.B.; Ray, C.; De Carlo, E.H. Calibration and validation of a physically distributed hydrological model, MIKE SHE, to predict streamflow at high frequency in a flashy mountainous Hawaii stream. J. Hydrol. 2006, 327, 94-109. [CrossRef]

71. Arnold, J.G.; Srinivasan, R.; Muttiah, R.S.; Williams, J.R. Large area hydrologic modeling and assesment Part I: Model development. J. Am. Water Resour. Assoc. 1998, 34, 73-89. [CrossRef]

72. Neitsch, S.L.; Arnold, J.G.; Kiniry, J.R.; Srinivasan, R.; Williams, J.R. Soil and Water Assessment Tool User's Manual; Springer: Berlin, Germany, 2002.

73. Arnold, J.G.; Kiniry, J.R.; Srinivasan, R.; Williams, J.R.; Haney, E.B.; Neitsch, S.L. Soil E Water Assessment Tool: Input/Output Documentation, version 2012; TR-439; Texas Water Resources Institute: College Station, TX, USA, 2013; Volume 650.

74. Pai, D.S.; Sridhar, L.; Rajeevan, M.; Sreejith, O.P.; Satbhai, N.S.; Mukhopadyay, B. Development of a new high spatial resolution $\left(0.25^{\circ} \times 0.25^{\circ}\right)$ Long Period (1901-2010) daily gridded rainfall data set over India and its comparison with existing data sets over the region. Mausam 2014, 65, 1-18.

75. Pai, D.S.; Sridhar, L.; Badwaik, M.R.; Rajeevan, M. Analysis of the daily rainfall events over India using a new long period $(1901-2010)$ high resolution $\left(0.25^{\circ} \times 0.25^{\circ}\right)$ gridded rainfall data set. Clim. Dyn. 2014, 45, 755-776. [CrossRef]

76. Rajeevan, M.; Bhate, J.; Kale, J.D.; Lal, B. High resolution daily gridded rainfall data for the Indian region: Analysis of break and active monsoon spells. Curr. Sci. 2006, 91, 296-306. 
77. Doorenbos, J.; Pruitt, W.O. Guidelines for predicting crop water requirements. FAO Irrig. Drain. Pap. 1977, $24,144$.

78. Drastig, K.; Prochnow, A.; Libra, J.; Koch, H.; Rolinski, S. Irrigation water demand of selected agricultural crops in Germany between 1902 and 2010. Sci. Total Environ. 2016, 569-570, 1299-1314. [CrossRef] [PubMed]

79. Brouwer, C.; Heibloem, M. Irrigation Water Management: Irrigation Water Needs. Rome Italy Food Agric. Organ. U. N. 1986, 7, 225-240.

80. Tennant, D.L. Instream flow regimens for fish, wildlife, recreation and related environmental resources. Fisheries 1976, 1, 6-10. [CrossRef]

81. Bekele, E.G.; Nicklow, J.W. Multiobjective management of ecosystem services by integrative watershed modeling and evolutionary algorithms. Water Resour. Res. 2005, 41. [CrossRef]

82. Haupt, R.L.; Haupt, S.E. Practical Genetic Algorithms; John Wiley \& Sons, Inc.: New York, NY, USA, 2006; Volume 18; ISBN 3540317589.

83. Srivastava, P.; Hamlett, J.M.; Robillard, P.D.; Day, R.L. Watershed optimization of best management practices using AnnAGNPS and a genetic algorithm. Water Resour. Res. 2002, 38. [CrossRef]

(C) 2018 by the authors. Licensee MDPI, Basel, Switzerland. This article is an open access article distributed under the terms and conditions of the Creative Commons Attribution (CC BY) license (http:/ / creativecommons.org/licenses/by/4.0/). 